\title{
B Cell Insensitivity in a Rat Model of Non-Insulin-dependent Diabetes Evidence for a Rapidly Reversible Effect of Previous Hyperglycemia
}

\author{
V. Grill, M. Westberg, and C.-G. Östenson \\ Department of Endocrinology, Karolinska Hospital, S-104 01 Stockholm, Sweden
}

\begin{abstract}
In perfused pancreas of rats rendered diabetic by streptozotocin injection (STZ) during neonatal age the insulin response to $27 \mathrm{mM}$ glucose was significant but impaired. It was unaffected by the alpha adrenergic blocker phentolamine. When $27 \mathrm{mM}$ mannoheptulose was added simultaneously with $27 \mathrm{mM}$ glucose, insulin release was inhibited, but less promptly than in pancreases from non-diabetic rats. When mannoheptulose was introduced 15 min after starting perfusion with $27 \mathrm{mM}$ glucose, inhibition was apparent in non-diabetic rats, but not in STZ. In non-diabetic rats perfusion without glucose for $\mathbf{4 0} \mathbf{m i n}$ failed to affect the subsequent response to $27 \mathrm{mM}$ glucose. Conversely, in STZ, glucose omission enhanced 3.7-fold the response to $27 \mathrm{mM}$ glucose. Insulin release in response to 3-isobutyl-1-methylxanthine (IBMX) was more marked in STZ than in non-diabetic rats. After glucose omission the IBMX-induced response was, however, reduced (67\%) in STZ, but not significantly (7\%) in non-diabetic rats.

Thus, glucopenia in vitro sensitizes B cells of STZ to glucose, but desensitizes them to IBMX. Abnormal responsiveness may be linked to metabolic consequences of $B$ cell fuel abundance.
\end{abstract}

\section{Introduction}

The insulin response to glucose is consistently diminished or abolished in humans with type II diabetes. The etiology of this abnormality is unclear. It may be part of the genetic predisposition (see reference 1 for review) for the disease. Alternatively, or additionally, it may result from disordered metabolism associated with the diabetic state. Studies in animals support this notion since insensitivity to glucose has been documented in various forms of non-insulin-dependent diabetes, including spontaneous (2) and toxin-induced (3) diabetes and diabetes after partial pancreatectomy (4). It follows that mechanisms of B cell insensitivity to glucose of possible relevance to type II diabetes in humans can be studied in vitro by the use of animal models.

We have studied B cell insensitivity to glucose in rats that developed diabetes as a result of streptozotocin treatment

This work was presented in part at the meeting of the American Diabetes Association, Anaheim, CA, June, 1986.

Address all correspondence and reprint requests to Dr. V. Grill, Department of Endocrinology, Karolinska Hospital, S-104 01 Stockholm, Sweden. 1987.

Received for publication 8 April 1986 and in revised form 15 April

J. Clin. Invest.

(c) The American Society for Clinical Investigation, Inc.

0021-9738/87/09/0664/06 \$2.00

Volume 80, September 1987, 664-669
$(\mathrm{STZ})^{1}$ during the neonatal period (5). The model has previously been developed and characterized by others $(3,6,7)$. Also, another abnormality of secretion was found, namely that the insulin response to non-nutrient secretagogues such as the phosphodiesterase inhibitor 3-isobutyl-1-methylxanthine (IBMX) was exaggerated and not influenced by the prevailing concentration of glucose $(2,5,8,9)$.

Previous results indicated that a severely reduced insulin response to glucose in the perfused pancreas could be partially restored by insulin treatment in vivo (5). Such treatment also restored the influence of glucose on the potency of other nonnutrient secretagogues (8). Although these results suggested the importance of hyperglycemia for the abnormalities of secretion, they did not allow the distinction whether elevated levels of glucose per se were responsible or if insensitivity was due to other factors associated with a diabetic state, which could potentially cause insensitivity. Such factors include circulating abnormal products of metabolism, hypoinsulinemia, as well as hypersecretion of hormones affecting B cell secretion, notably catecholamines that inhibit insulin secretion through stimulation of alpha adrenergic receptors $(1,10)$.

The purpose of the present study was to test in vitro, first, whether abnormal secretion could to a major extent be due to tonic inhibition of insulin secretion by alpha adrenergic receptor activity. When our results failed to support this notion, we investigated whether the previous hyperglycemia per se and/or its metabolic consequences in the B cell was important for abnormalities in insulin secretion. To this end we tested the effects of mannoheptulose, an agent documented to inhibit both ATP: glucose-6-phosphotransferase activity and glucoseinduced insulin secretion (11). Furthermore, we investigated whether glucopenia in vitro could enhance B cell sensitivity to glucose in STZ and, if so, whether the same procedure would reciprocally affect the insulin response to non-nutrient secretagogues. Our results indicate that B cell fuel abundance and its metabolic consequences play an important role for the abnormalities of insulin secretion in STZ.

\section{Methods}

Animals. Lactating Sprague-Dawley rats with their offspring were obtained from ALAB, Stockholm, Sweden the day after delivery. On the same day male and female pups were injected with $90 \mathrm{mg} / \mathrm{kg}$ of streptozotocin (kindly supplied by Dr. William E. Dulin, Upjohn Co., Kalamazoo, MI). Streptozotocin was dissolved immediately before intraperitoneal injection in citrate buffer $(10 \mathrm{mM}, \mathrm{pH} 4.5)$ to yield a concentration of $9 \mathrm{mg} / \mathrm{ml}(34 \mathrm{mM})$. Litter sizes were between 10 and 15 animals. Pups from control litters received citrate buffer alone. $2 \mathrm{~d}$ after injections, a specimen of whole blood was obtained by tail-vein incision to determine blood glucose by a glucose-oxidase method using reagents strips (Reflotest; Boehringer Mannheim $\mathrm{GmbH}$, Mannheim, FRG) read for absorbance in a reflectance meter (Reflo-

1. Abbreviations used in this paper: IBMX, 3-isobutyl-1-methylxanthine; STZ, streptozotocin-diabetic rats. 
mat, Boehringer Mannheim GmbH, Mannheim, FRG). Streptozotocin-injected animals were included in the study if their blood glucose was $10 \mathrm{mM}$ or above. Blood glucose in non-injected pups of this age was $4.06 \pm 0.32 \mathrm{mM}$, mean \pm SEM of six litters. Animals were weaned between 21 and $28 \mathrm{~d}$ of age after which they were fed a standard pelleted diet (ALAB).

STZ and control animals of both sexes between 6 and 10 wk of age were used for experiments. All series of experiments included animals from more than one litter to minimize the influence of litter-dependent variation on the results. In the morning on the day of the experiment a blood glucose determination was obtained by tail incision.

Perfused pancreas preparation. The animals were anaesthetized by the intraperitoneal injection of $100 \mathrm{mg} / \mathrm{kg}$ body wt of pentobarbital. The pancreas was isolated free from adjacent organs, as described (12). The pancreas was perfused through the abdominal aorta with a Krebs-Henseleit bicarbonate buffer (13) containing $20 \mathrm{~g} /$ liter of bovine albumin (Sigma Chemical Co., St. Louis, MO) and, when not otherwise indicated, $3.9 \mathrm{mM}$ of glucose. The Kreb's-Henseleit bicarbonate buffer medium was continuously gassed with a mixture of $95 \%$ $\mathrm{O}_{2}$ and $5 \% \mathrm{CO}_{2}$. A 20-min period (not recorded in the figures or tables) of perfusion with this medium was always allowed before the start of the actual protocol. The latter time point was designated as zero minute. The agents tested were all obtained from Sigma Chemical Co.

In all protocols, samples of the perfusate were collected, at times indicated on the figures, into prechilled tubes, then frozen, and stored at $-20^{\circ} \mathrm{C}$

Extraction of insulin. At the end of experiments, perfused pancreases were rapidly frozen. They were then kept at $-70^{\circ} \mathrm{C}$ until extraction of insulin was performed in perfused pancreas, as previously described (14).

Assays. Insulin was measured radioimmunologically using charcoal addition to separate free and bound antibody (15). The sensitivity of this assay was $8 \mathrm{mU} /$ liter and the interassay coefficient of variation, $\pm 10 \%$.

Presentation of results. Results are expressed as means \pm SEM. Integrated responses were calculated as the increment above secretion rates recorded immediately before the administration of test substances. Tests of significance were carried out using two-tailed Student's $t$ test for unpaired differences.

\section{Results}

Blood glucose, weight, and pancreatic content of insulin in streptozotocin-injected rats. Rats injected with streptozotocin were slightly hyperglycemic between 6 and 10 wk of age (Table I). Body weight was similar to non-diabetic animals of the same age. The mean pancreatic insulin content was reduced to $34 \%$ of non-diabetic pancreases.

Effects of phentolamine on glucose-induced insulin secretion. In perfused pancreas from STZ $27 \mathrm{mM}$ glucose induced a small but significant insulin response $(1,540 \pm 296 \mu \mathrm{U} / 20 \mathrm{~min}$, $P<0.05)$. This response was only $7 \%$ of that in pancreas from

Table I. Blood Glucose, Weight, and Pancreatic Insulin Content of Animals under Study

\begin{tabular}{llll}
\hline Rats & Weight & Blood glucose & $\begin{array}{l}\text { Pancreatic insulin } \\
\text { content }\end{array}$ \\
\hline & $g$ & $m M$ & mU/pancreas \\
& & & $2,063 \pm 169$ \\
Nondiabetic & $214 \pm 8(27)^{*}$ & $4.54 \pm 0.18(18)$ & $(20)$ \\
STZ & $221 \pm 6(46)$ & $7.91 \pm 0.49^{\ddagger}(43)$ & $704 \pm 58^{\ddagger}(35)$
\end{tabular}

* Number of observations.

* Significance of difference, $P<0.001$ vs. nondiabetic.
Table II. Effects of Glucopenia on Subsequent Insulin Response to $27 \mathrm{mM}$ Glucose

\begin{tabular}{|c|c|c|c|c|c|}
\hline \multirow[b]{2}{*}{ Rats } & \multirow[b]{2}{*}{ Line } & \multirow{2}{*}{$\begin{array}{l}\text { No. of } \\
\text { experiments }\end{array}$} & \multicolumn{2}{|c|}{$\begin{array}{l}\text { Concentrations of } \\
\text { glucose }\end{array}$} & \multirow{2}{*}{$\begin{array}{l}\text { Glucose-induced } \\
\text { insulin release }\end{array}$} \\
\hline & & & Amount & Time & \\
\hline & & & $m M$ & $\min$ & $\mu U / 20 \min$ \\
\hline \multirow[t]{7}{*}{ Nondiabetic } & 1 & 8 & 3.9 & $0-10$ & $21,494 \pm 3,776$ \\
\hline & & & 27 & $10-30$ & \\
\hline & 2 & 4 & 3.9 & $0-50$ & $24,741 \pm 1,574$ \\
\hline & & & 27 & $50-70$ & \\
\hline & 3 & 7 & 3.9 & $0-10$ & $20,948 \pm 1,214$ \\
\hline & & & 0 & $10-50$ & \\
\hline & & & 27 & $50-70$ & \\
\hline \multirow[t]{7}{*}{ STZ } & 4 & 6 & 3.9 & $0-10$ & $1,540 \pm 296$ \\
\hline & & & 27 & $10-30$ & \\
\hline & 5 & 6 & 3.9 & $0-50$ & $2,219 \pm 601$ \\
\hline & & & 27 & $50-70$ & \\
\hline & 6 & 6 & 3.9 & $0-10$ & $5,712 \pm 1,344^{*}$ \\
\hline & & & 0 & $10-50$ & \\
\hline & & & 27 & $50-70$ & \\
\hline
\end{tabular}

Results are derived from Fig. 3 and are expressed as means \pm SEM of incremental responses (immediately preceding secretion rates are subtracted) to $27 \mathrm{mM}$ glucose.

* Significance of difference vs. lines 4 and $5 ; P<0.02$.

non-diabetic rats (Table II). Perfusion with $10 \mu \mathrm{M}$ phentolamine, which was started 10 min before the introduction of 27 $\mathrm{mM}$ glucose, failed to significantly enhance the response to 27 $\mathrm{mM}$ glucose seen in the absence of the alpha adrenergic blocking agent (Fig. 1). The incremental response to glucose was thus $1,696 \pm 282 / 20 \mathrm{~min}$ in the presence of phentolamine, i.e., $110 \%$ of the response in the absence of this agent.

Effects of mannoheptulose on glucose-induced insulin secretion. When mannoheptulose was introduced together with $27 \mathrm{mM}$ glucose (Fig. 2, left, top and bottom), the heptose promptly and almost completely inhibited glucose-induced insulin secretion from non-diabetic rats. More than $90 \%$ inhibition was thus seen already after 2 min of perfusion with mannoheptulose. In STZ, on the other hand, mannoheptulose failed to inhibit glucose-induced insulin secretion when measured after 2 min of drug perfusion; secretion rates were thus

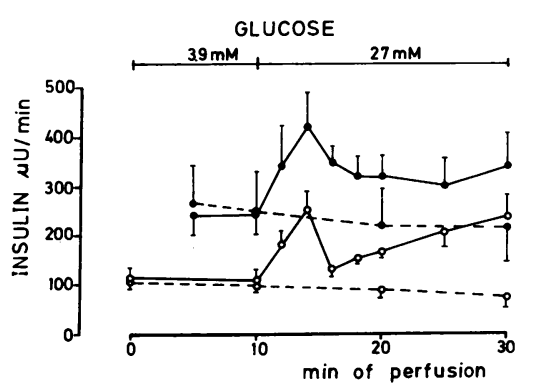
of phentolamine ( 10 $\mu \mathrm{M})$ on glucose-induced insulin release in STZ. Mean \pm SEM of $n=4-6$ for each experimental condition. $27(-\mathrm{O}-)$ and $3.9 \mathrm{mM}(--\mathrm{O}--)$ glucose in absence of phentolamine. 27 $(-0)$ and $3.9 \mathrm{mM}$ (-- - --) glucose in presence of phentolamine. 
NON-DIABETIC

GLUCOSE $39 \mathrm{mM}$ GLUCOSE $27 \mathrm{mM}$

MANNOHEPTULOSE

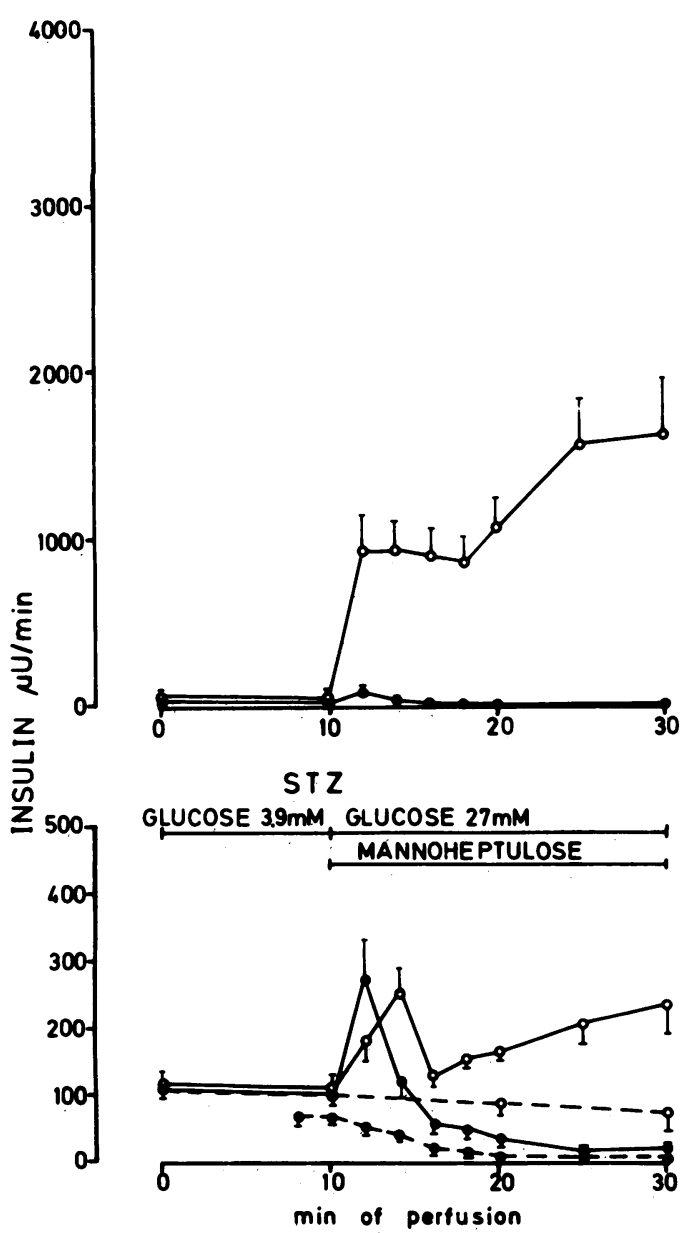

NON-DIABETIC

GLUCOSE $27 \mathrm{mM}$

MANNOHEPTUYOSE

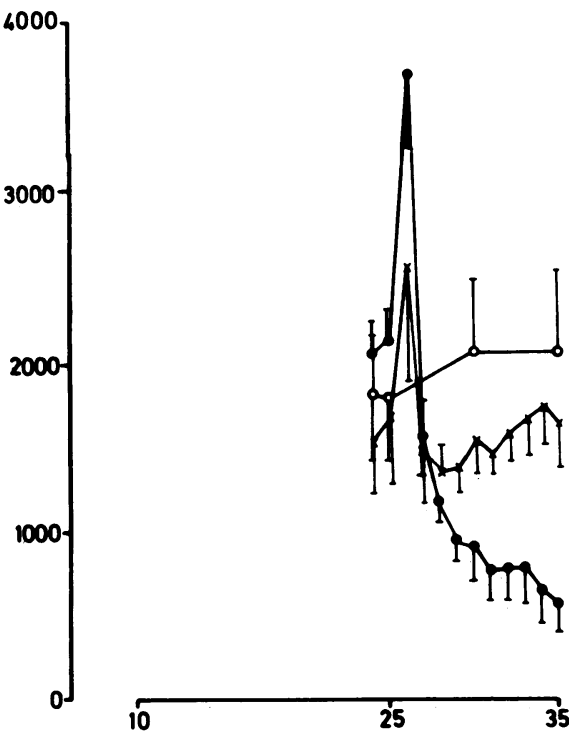

ST Z

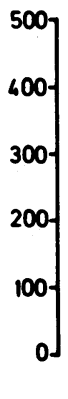

GLUCOSE $27 \mathrm{mM}$

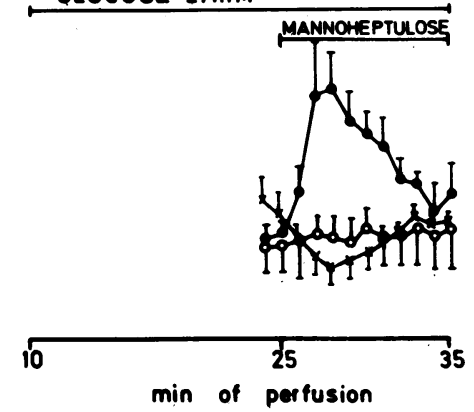

Figure 2. Effects of mannoheptulose (27 $\mathrm{mM}$ ) on glucose-induced insulin secretion. Filled symbols denote incubations with; and open symbols, without mannoheptulose. Incubations with $27 \mathrm{mM}$ glucose and 27 $\mathrm{mM}$ sucrose are denoted $-\mathrm{X}-$ (top and bottom right). Solid lines indicate experiments that included stimulation with $27 \mathrm{mM}$ glucose; and broken lines, experiments where the glucose concentration was kept constant at $3.9 \mathrm{mM}$. Two experimental series without mannoheptulose (bottom left) are from Fig. 1. The control experiments $(27 \mathrm{mM}$ glucose alone) (right and left) constitute separate series. Mean \pm SEM of $n=4-6$. Note the different scales on upper and lower graphs.
$180 \pm 29 \mu \mathrm{U} / \mathrm{min}$ in the absence of the drug and $273 \pm 61 \mu \mathrm{U} /$ min in the presence of the heptose. However, the continued presence of mannoheptulose successively inhibited secretion in the presence of $27 \mathrm{mM}$ glucose and also of $3.9 \mathrm{mM}$ glucose.

When mannoheptulose was added to the perfusion medium $15 \mathrm{~min}$ after the start of perfusion with $27 \mathrm{mM}$ glucose, a paradoxical stimulation was observed in pancreas from nondiabetic rats (Fig. 2, top right). This effect of mannoheptulose was brief and followed by progressive inhibition of glucose-induced insulin secretion. The mean secretion rate of insulin during a 10-min period after the introduction of mannoheptulose was thus $2,122 \pm 188 \mu \mathrm{U} / \mathrm{min}$ in the absence and $1,171 \pm 430 \mu \mathrm{U} / \mathrm{min}$ in the presence of mannoheptulose. This difference amounted to a $44 \%$ inhibition $(P<0.01)$.

When the same protocol was tested in STZ, mannoheptulose stimulated insulin secretion throughout a 10-min period after the introduction of the heptose. The mean secretion rate during this period was thus $153 \pm 51 \mu \mathrm{U} / \mathrm{min}$ in the absence and $268 \pm 35 \mu \mathrm{U} / \mathrm{min}$ in the presence of the heptose. This difference amounted to a $75 \%$ stimulation by the heptose $(P$ $<0.05$ ).

The possibility that the stimulatory effects of mannoheptulose would be a non-specific osmotic effect was considered. Experiments were therefore performed with the addition of 27
mM sucrose, instead of mannoheptulose, during an ongoing stimulation with $27 \mathrm{mM}$ glucose. In non-diabetic rats a moderate but transient stimulation was indeed seen after addition of sucrose (Fig. 2, top right). In STZ, however, addition of sucrose completely failed to enhance insulin secretion (Fig. 2, bottom right).

Effects of glucopenia on glucose-induced insulin secretion. In non-diabetic rats, preperfusion with a medium containing "basal" glucose $(3.9 \mathrm{mM})$ or no glucose did not affect the integrated insulin response to subsequent stimulation with 27 $\mathrm{mM}$ glucose (Fig. 3, Table II). Nor was the initial insulin response, i.e., that recorded during the first $6 \mathrm{~min}$, significantly altered: it was $5,118 \pm 992,4,806 \pm 1336$, and $6,580 \pm 667 \mu \mathrm{U}$ per 6 min (mean $\pm S E M$ ) for early perfusion, preperfusion with basal, and preperfusion with no glucose, respectively. Conversely, in STZ, the insulin response to glucose after glucose omission was enhanced 3.7-fold relative to stimulation shortly after isolation and 2.6-fold relative to experiments where preperfusion with $3.9 \mathrm{mM}$ glucose had been carried out (Fig. 3, Table II). Relative to release in non-diabetic rats, glucopenia increased the response in STZ from 7 to $27 \%$.

Effects of glucopenia on IBMX-induced insulin secretion. When IBMX was tested early during perfusion (in the absence of glucose), the phosphodiesterase inhibitor evoked im- 


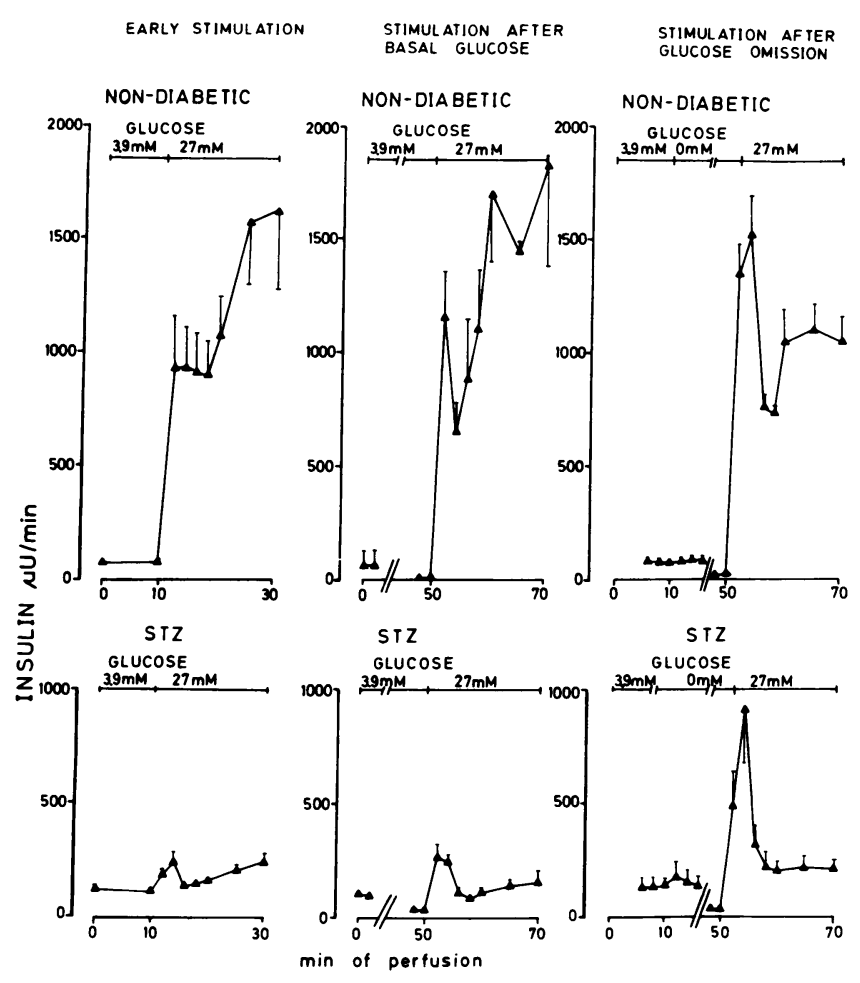

Figure 3. Effects of glucopenia on glucose-induced insulin secretion. Responses to $27 \mathrm{mM}$ glucose early during perfusion (left) are taken from Figs. 1 and 2. Glucose was kept constant at $3.9 \mathrm{mM}$ between zero and minute 50 or omitted between minutes 10 and 50 of the protocols presented in the middle and right graphs, respectively. Mean \pm SEM of 4-8 experiments in each series.

pressive insulin release in STZ, which was significantly more marked than that in pancreases from non-diabetic animals (Fig. 4). The integrated IBMX-induced response was thus $12,385 \pm 2,412 \mu \mathrm{U}$ per $20 \mathrm{~min}$ in $\mathrm{STZ}$ and $6,495 \pm 1,525 \mu \mathrm{U}$ in non-diabetic rats, $P<0.05$ for difference. When, in separate experiments, IBMX was tested after a $40-\mathrm{min}$ period of glucose omission, the response in STZ had declined to $4,069 \pm 1,320$, i.e., by $67 \%$ relative to experiments where IBMX was introduced earlier. Conversely, in non-diabetic rats the period of glucopenia did not alter the response to the phosphodiesterase inhibitor. The response was thus $6,052 \pm 1,610$ $\mu \mathrm{U}$ per $20 \mathrm{~min}$ after the period of glucose omission, which was only $7 \%$ lower than the response seen before glucopenia.

\section{Discussion}

This study indicates that hyperglycemia per se is responsible, at least in part, for the abnormalities of insulin secretion in STZ. Our results thus show that perfusion with a glucose-free medium markedly increased the insulin response to glucose. This increase was apparent whether in comparison with the response obtained shortly after the isolation of the pancreas or that in a time-matched protocol where the pancreas was preperfused with a basal concentration of glucose. A previous study (5), furthermore, demonstrated that prior perfusion with a high glucose concentration failed to increase the subsequent response to $27 \mathrm{mM}$ glucose and, in fact, diminished it in relation to the augmented glucose-primed response seen in non-

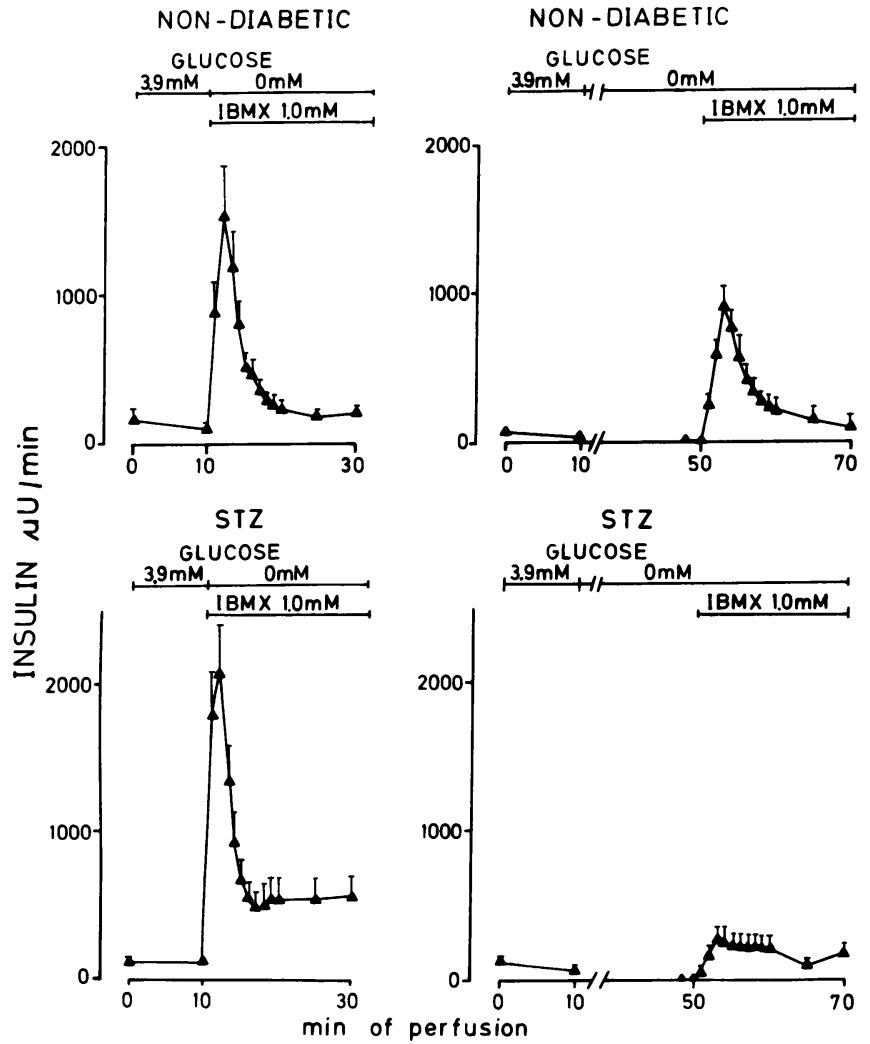

Figure 4. Effects of glucopenia on IBMX-induced insulin secretion. Glucose was omitted between minutes 10 and 50 of the protocols presented in the right top and bottom graphs. Mean \pm SEM of 4-6 experiments for each condition.

diabetic rats. The effect of glucose omission seemed, at least to a major part, specific for STZ since glucose omission failed to exert a significant effect on the subsequent response to glucose in pancreas from non-diabetic rats; consequently, the ratio of response to glucose between STZ and non-diabetic rats increased by several folds.

Alpha adrenergic receptor stimulation is known to inhibit insulin secretion (1) and has been suggested to participate in glucose insensitivity in non-insulin-dependent diabetes mellitus (10). It thus seemed possible that increased stimulation of these receptors on the pancreatic B cells of STZ could give rise to apparent insensitivity to glucose. In the present experiments, however, addition of the alpha adrenergic blocking agent phentolamine failed to influence glucose-induced insulin secretion in STZ. These negative results support the notion of a major role for hyperglycemia per se rather than hormonal abnormalities in determining insensitivity to glucose.

Omission of glucose in STZ was associated not only with enhanced insulin response to glucose but also with markedly diminished response to the phosphodiesterase inhibitor IBMX. The exaggerated response to this secretagogue in STZ, which has previously been documented (5), was thus markedly diminished after glucopenia. The response was reduced both in absolute terms and, more importantly, in relation to nondiabetic rats. Hence glucopenia, when present for the same period of time in vitro, partly normalized two recognized abnormalities of insulin secretion in STZ in comparison to nondiabetic rats: insensitivity to glucose and supersensitivity to 
non-nutrient secretagogues. These similarities raise the question whether a common mechanism may underlie both abnormalities.

Possible mechanisms behind an enhanced response to a non-nutrient secretagogue such as IBMX are easier to envisage than those underlying an impaired response to glucose. Since some or several steps of insulin secretion are energy dependent (16), it follows that availability of endogenous substrates could limit the insulin response to non-nutrient secretagogues when tested in the absence of exogenous fuels. It is also well-known that diabetes (17) as well as short-term hyperglycemia (18) lead to increased amounts of glycogen in islets. Reciprocally, glycogen stores are rapidly depleted by fuel deprivation or anoxia (18). Furthermore, increased glycogen stores have been associated with increased responsiveness to IBMX (19). Hence, it seems likely that increased levels of endogenous substrates, whether in the form of glycogen or not, could underlie the enhanced response to IBMX in STZ and that glucose omission could decrease an enhanced response to IBMX by decreasing levels of endogenous substrates needed for secretion.

The mechanisms behind a possible effect of fuel abundance on glucose-induced insulin secretion can only be speculated upon. Nutrient-induced insulin secretion requires normal B cell metabolism (20); an altered metabolism of exogenous glucose in B cells of STZ could therefore be suspected. A situation of fuel abundance can suppress glycolysis in many cell types as a result of allosteric inhibition by, for instance, citrate, ATP, NADH, and NADPH (21). Evidence that such a Pasteur effect is operative also in pancreatic islets is lacking (22), but cannot be ruled out. Interference with the signal for secretion normally exerted by exogenous glucose could also arise through the breakdown of glycogen. This would increase the level of glucose intermediates and possibly also the level of free intracellular glucose. The latter effect requires glucose-6phosphatase activity, which may be increased in a diabetic state (23). However, the observation that the insulin release in STZ is impaired not only in response to glucose but also to other nutrients such as alpha ketoisocaproic acid (5) suggests that oxidative metabolism is impaired in the diabetic B cell. It seems possible that fuel abundance could occur also in the form of endogenous lipids (24), which could feed into the Krebs cycle, thereby inhibiting the oxidation of other fuels. Needless to say, all these notions require future experimental testing.

In the present context it should also be mentioned that the notion of altered metabolism in STZ is seemingly contradicted by observations in isolated islets where glucose utilization (25) and glucose oxidation (26) were found to be similar in islets from non-diabetic rats and STZ. The isolated islet of STZ is, however, for unknown reasons, more sensitive to glucose in terms of insulin secretion than is the perfused pancreas (26, 27). If glucose metabolism determines an insulin response, then the metabolic data available do not wholly reflect the situation in perfused pancreas or in vivo.

The results with mannoheptulose in STZ could indicate that the heptose exerts its usual inhibitory effect on glucose metabolism (28-30). This effect could then relieve the B cell from putative effects of fuel abundance and thereby increase $B$ cell sensitivity to glucose as secretagogue. The observation that transition from a high to a low concentration of glucose in the perfusate enhances secretion (31) supports this notion. Alter- natively, diabetes protects against mannoheptulose action on its target in the B cell. Mannoheptulose inhibits glycolysis at its earliest stage, i.e., at the level of ATP: glucose-6-phosphotransferase activity (glucokinase-hexokinase, 11, 28-30). Studies employing the use of other inhibitors, such as alloxan, indicate that glucose per se rather than its metabolic consequences protects the glucokinase enzyme in islets (32). Decreased inhibition of insulin release may thus be coupled to increased levels of intracellular glucose. This could explain why mannoheptulose inhibited less rapidly when introduced during, rather than together with, a glucose stimulus.

The finding of a stimulatory effect of mannoheptulose is intriguing. This effect was seen only when mannoheptulose was added during ongoing stimulation with glucose; osmotic control experiments revealed that the effect was specific for the heptose only in STZ. As outlined above, the stimulation may be related to inhibition of glucose metabolism and relief from fuel abundance. However, the effect could also be due to mannoheptulose interaction with a site different from glucokinase-hexokinase. A similar paradoxical enhancement has been observed when the inhibitor was tested together with D-glyceraldehyde (33). It seems possible that the stimulatory effect is unmasked in situations where the inhibitory effect is attenuated or abolished.

\section{Acknowledgments}

Expert secretarial assistance was provided by Mrs. Sylvie Karlsson.

This work was supported by the Swedish Medical Research Council (grant 19x-04540), The Swedish Diabetes Association, and the Nordic Insulin Foundation.

\section{References}

1. Ward, W. K., J. C. Beard, J. B. Halter, M. A. Pfeifer, and D. Porte. 1984. Pathophysiology of insulin secretion in non-insulin dependent diabetes mellitus. Diabetes Care. 7:491-502.

2. Grill, V., and L. Herberg. 1983. Glucose- and arginine-induced insulin and glucagon responses from the isolated perfused pancreas of the BB-Wistar diabetic rat. Evidence for selective impairment of glucose regulation. Acta Endocrinol. 102:561-566.

3. Weir, G. C., E. T. Cloré, C. J. Zmachinski, and S. Bonner-Weir. 1981. Islets secretion in a new experimental model for non-insulin-dependent diabetes. Diabetes. 30:590-595.

4. Bonner-Weir, S., D. F. Trent, and G. C. Weir. 1983. Partial pancreatectomy in the rat and subsequent defect in glucose-induced insulin release. J. Clin. Invest. 71:1544-1553.

5. Grill, V., and M. Rundfeldt. 1986. Abnormalities of insulin responses after ambient and previous exposure to glucose in streptozotocin-diabetic and dexamethasone-treated rats. Role of hyperglycemia and increased B-cell demands. Diabetes. 35:44-51.

6. Portha, B., C. Levacher, L. Picon, and G. Rosselin. 1974. Diabetogenic effect of streptozotocin in the rat during the perinatal period. Diabetes. 23:889-895.

7. Bonner-Weir, S., D. F. Trent, R. N. Honey, and G. C. Weir. 1981. Responses of neonatal rat islets to streptozotocin. Limited B-cell regeneration and hyperglycemia. Diabetes. 30:64-69.

8. Leahy, J. L., S. Bonner-Weir, and G. C. Weir. 1985. Abnormal insulin secretion in a streptozotocin model of diabetes. Effects of insulin treatment. Diabetes. 34:660-666.

9. Giroix, M.-H., B. Portha, M. Kergoat, D. Bailbe, and L. Picon. 1985. Glucose insensitivity and amino-acid hypersensitivity of insulin release in rats with non-insulin dependent diabetes. A study with the perfused pancreas. Diabetes. 32:445-451. 
10. Robertson, R. P., J. B. Halter, and D. Porte. 1976. A role for alpha-adrenergic receptors in abnormal insulin secretion in diabetes mellitus. J. Clin. Invest. 57:791-795.

11. Coore, H. G., and P. J. Randle. 1964. Inhibition of glucose phosphorylation by mannoheptulose. Biochem. J. 91:56-59.

12. Loubatières, A. L., M. M. Mariani, G. Ribes, H. de Malbosc, and J. Chapal. 1969. Étude expérimental d'un nouveau sulfamide hypoglycémiant particulierement actif le HB419 ou glibenclamide. Diabetologia. 5:1-10.

13. Umbreit, W. W., R. H. Burris, and J. F. Stauffer. 1957. Manometric Techniques. Burgess Publish Co., Minneapolis. 149-150.

14. Grill, V., M. Rundfeldt, and S. Efendic. 1981. Previous exposure to glucose enhances somatostatin secretion from the isolated perfused rat pancreas. Diabetologia. 20:495-500.

15. Herbert, V., K. S. Lau, C. W. Gottlieb, and S. J. Bleicher. 1965. Coated charcoal immunoassay of insulin. J. Clin. Endocrinol. \& Metab. 25:1375-1384.

16. Hellerström, C., and S. Brolin. 1975. Energy metabolism of the B-cell. In Handbook of Experimental Pharmacology. Springer-Verlag, Heidelberg. 58-78.

17. Duff, L. G., and W. E. Toreson. 1951. Prevention and reversal despite hyperglycemia of glycogen infiltration ("hydropic degeneration") in the pancreas of alloxan diabetes in the rabbit. Endocrinology. 48:298-312.

18. Hellman, B., and L.-Å. Idahl. 1969. Presence and mobilization of glycogen in mammalian pancreatic B-cells. Endocrinology. 84:1-8.

19. Malaisse, W. J., A. Sener, M. Koser, M. Ravazzola, and F. Malaisse-Lagae. 1977. The stimulus-secretion coupling of glucose-induced insulin release. Insulin release due to glycogenolysis in glucosedeprived islets. Biochem. J. 164:447-454.

20. Ashcroft, S. J. H. 1980. Glucoreceptor mechanisms and the control of insulin release and biosynthesis. Diabetologia. 18:5-15.

21. Lehninger, A. 1975. Integration of glycolysis and respiration. In Biochemistry. A. Lehninger, editor. Worth Publishers Inc., New York. 536-539.

22. Hellman, B., L.-Å. Idahl, J. Sehlin, and I.-B. Täljedal. 1975. Influence of anoxia on glucose metabolism in pancreatic islets: lack of correlation between fructose-1.6-diphosphate and apparent glycolytic flux. Diabetologia. 11:495-500.
23. Täljedal, I.-B. 1969. Presence, induction and possible role of glucose-6-phosphatase in mammalian pancreatic islets. Biochem. $J$. 114:387-394.

24. Malaisse, W. J., F. Malaisse-Lagae, A. Sener, and C. Hellerström. 1985. Participation of endogenous fatty acids in the secretory activity of the pancreatic B-cell. Biochem. J. 227:995-1002.

25. Colella, R. M., J. M. May, S. Bonner-Weir, J. L. Leahy, and G. C. Weir. 1987. Glucose utilization in islets of hyperglycemic rat models with impaired glucose-induced insulin secretion. Metabolism. 36:335-337.

26. Östenson, C.-G. 1985. High glucose culture enhances glucoseinduced insulin release and maintains islet insulin content in isolated pancreatic islets from a rat model of NIDDM. Diab. Res. Clin. Pract. 1:S427. (Abstr.)

27. Halban, P. A., S. Bonner-Weir, and G. C. Weir. 1983. Elevated proinsulin biosynthesis in vitro from a rat model of non-insulin-dependent diabetes mellitus. Diabetes. 32:277-283.

28. Ashcroft, S. J. H., S. J. Hedeskov, and P. J. Randle. 1970. Glucose metabolism in mouse pancreatic islets. Biochem. J. 118:143154.

29. Zawalich, W. S., E. S. Dye, R. Rognstad, and F. M. Matschinsky. 1978. On the biochemical nature of triose- and hexose-stimulated insulin secretion. Endocrinology. 103:2027-2034.

30. Malaisse, W. J., A. Sener, and J. Leverö. 1976. The stimulussecretion coupling of glucose-induced insulin release. Fasting-induced adaptation in key glycolytic enzymes in isolated islets. J. Biol. Chem. 251:1731-1737.

31. Leahy, J. L., and G. C. Weir. 1985. Unresponsiveness to glucose in a streptozotocin model of diabetes: inappropriate insulin and glucagon responses to a reduction of glucose concentration. Diabetes. 34:635-659.

32. Meglasson, M. D., P-T. Burch, D. K. Berner, H. Najafi, and F. M. Matschinsky. 1986. Identification of glucokinase as an alloxansensitive glucose sensor of the pancreatic B-cell. Diabetes. 35:11631173.

33. Hellman, B., L.-Å. Idahl, Å. Lernmark, J. Sehlin, and I.-B. Täljedal. 1973. The pancreatic B-cell recognition of insulin secretagogues. Comparison of glucose with glyceraldehyde isomers and dihydroxyacetone. Arch. Biochem. Biophys. 162:448-457. 